\title{
Work and Well-being in an Aging Society
}

\author{
Lars Osberg \\ Department of Economics \\ Dalhousie University \\ 6214 University Ave. \\ Halifax, Nova Scotia \\ CANADA \\ Lars.Osberg@dal.ca \\ $30 / 11 / 05$
}

What policy, or set of policies, will most improve the economic well-being of Canadians? Because the aging of Canadian society will be a crucial part of the context of Canadian economic and social policy over the next few decades, this paper argues that the well-being of all Canadians is likely to be increased by policies that make it easier for individuals to smooth their labour supply more evenly over the life cycle. Greater smoothing of labour supply would have benefits for both younger and older cohorts, by implying both a less hectic middle-age and continued contribution, and involvement, by older Canadians. However, if a longer period of paid employment is to represent an improvement in individual well-being, it must be due to choice, not necessity. Hence, welfare improving policies to even out labour supply over the life cycle should be complemented by policies that help individuals even out the income fluctuations which they experience during their working lives.

The perspective underlying this paper is the proposition that improving economic well-being is not necessarily the same as increasing Gross Domestic Product (GDP) per capita or maximizing the growth rate of GDP. GDP measures the marketed output of the Canadian economy ${ }^{1}$, but market goods and services are not an end in themselves - rather they are inputs to the utility functions of individuals. Goods and services may help produce utility, but other things - like leisure - also matter, and the distinction between utility and income is particularly important when we consider a decision, like retirement, that is all about whether to enjoy more leisure or more income. After all, since GDP is a measure that ascribes zero importance to leisure time, using per capita GDP as a criterion implies that more output and more paid work is always better, whatever the cost in nonwork time. Canada's GDP per capita would rise substantially if Canadian law was changed to abolish retirement entirely - and to outlaw vacations, weekends and holidays - but few of us would consider this an improvement in well-being.

Furthermore, it is worth distinguishing between individual utility at a point in time, or individual welfare over a lifetime, or national well-being aggregated across individuals. Implicitly or explicitly, any measure of "Canadian economic well-being" has to aggregate over the different years of individuals' lives and across the disparate lifetime fortunes of individuals. The problem with measures of well-being such as the growth rate of GDP, or per capita GDP, is that individual variations all net out. Although some

\footnotetext{
${ }^{1}$ To be exact, since GDP measures the output which occurs in Canada, while Gross National Product (GNP) measures the output produced by factors of production owned by Canadians, it is GNP that determines the market incomes of Canadians.
} 
people will be above average and some below - perhaps temporarily or perhaps not these deviations cancel out in the calculation of averages. When one looks only at averages, one ignores the fact that individual utility at each point in time will certainly be affected both by relative income position and by the prospects of its future stability, and that income inequality and economic insecurity consequently will affect individuals' lifetime welfare ${ }^{2}$.

As it happens, deviations from average, "per capita" labour supply are particularly important for analysis of demographic change. In Canada, a striking feature of our labour market institutions is the fact that they concentrate most individuals' paid work hours into a relatively few decades in the middle of their lives. It is not unusual to complete postsecondary education in one's early twenties, and retire on full pension after thirty five years of employment, yet live to one's late eighties or beyond - a scenario which implies that the period of paid work effort comprises only about the middle $40 \%$ of the life cycle. Coincidentally, unpaid work in the home is simultaneously concentrated heavily in the early middle age period when both parents of young children typically are employed full time, at their peak period of paid labour supply. As a consequence, individuals then experience years of totally hectic time crunch, when hobbies, interests and social contacts outside the family often atrophy from disuse, because there is simply not the time to maintain them. However, a few years later, the same individuals can often find the transition from $100 \%$ effort to $0 \%$ to be disconcertingly abrupt. Since the institution of retirement is still often currently constructed as a complete cessation of paid work, the years of "no time to do it all" can be suddenly followed by the problem of "nothing to do all day".

Although some individuals have found ways to adjust marginally their labour supply - e.g. by part-time post retirement jobs - the more basic question is: "Why do we organize our lives in this way?" When both utility in middle age and utility in senior years could plausibly be increased by a transfer of leisure time from later life to middle years, offset by an equivalent transfer of paid activity from middle age to senior years, why do Canadian labour market institutions make this so difficult?

The peak loading of labour supply years is particularly hard to understand as optimal in a society with a demographically uneven population, since peak loading magnifies the impact of differential cohort size on the size of the paid labour force. The greater the differentials in cohort size, and the more rigidly paid labour supply is restricted to middle age, the more the total amount of market work - and the taxes paid on it - will be affected over time by demographic unevenness. Governments in many countries are rightly concerned. The trend to smaller middle age cohorts in an aging, longer lived population implies that the fiscal crunch of declining revenues from payroll and income taxes on earned income will be combined with increasing expenditures on pensions and services for senior citizens.

Canada, like many other developed nations, has therefore been concerned about demographic trends for some time. The OECD, Department of Finance, HRSDC and Policy Research Initiative are only a few of the institutions that have published excellent recent analyses of the labour force and economic growth implications of Canada's aging population. Figure 1 is taken from the PRI study and summarizes a major theme of most of these documents - the fact that a fairly small increase in the average age of retirement

\footnotetext{
${ }^{2}$ For a fuller discussion, see Osberg and Sharpe (2005)
} 
can have major implications on the impact which population aging would otherwise have on the supply of labour hours. As Figure 1 illustrates, an increase of two years in average working life would mean that labour supply, measured on an hours per capita of the total population basis, would continue to rise for the next decade in Canada and would still be above current levels in 2025.

\section{Figure 1}

Impact of Extending Working Life by Two Years: Total Labour Supply per Capita,* 2000-2025

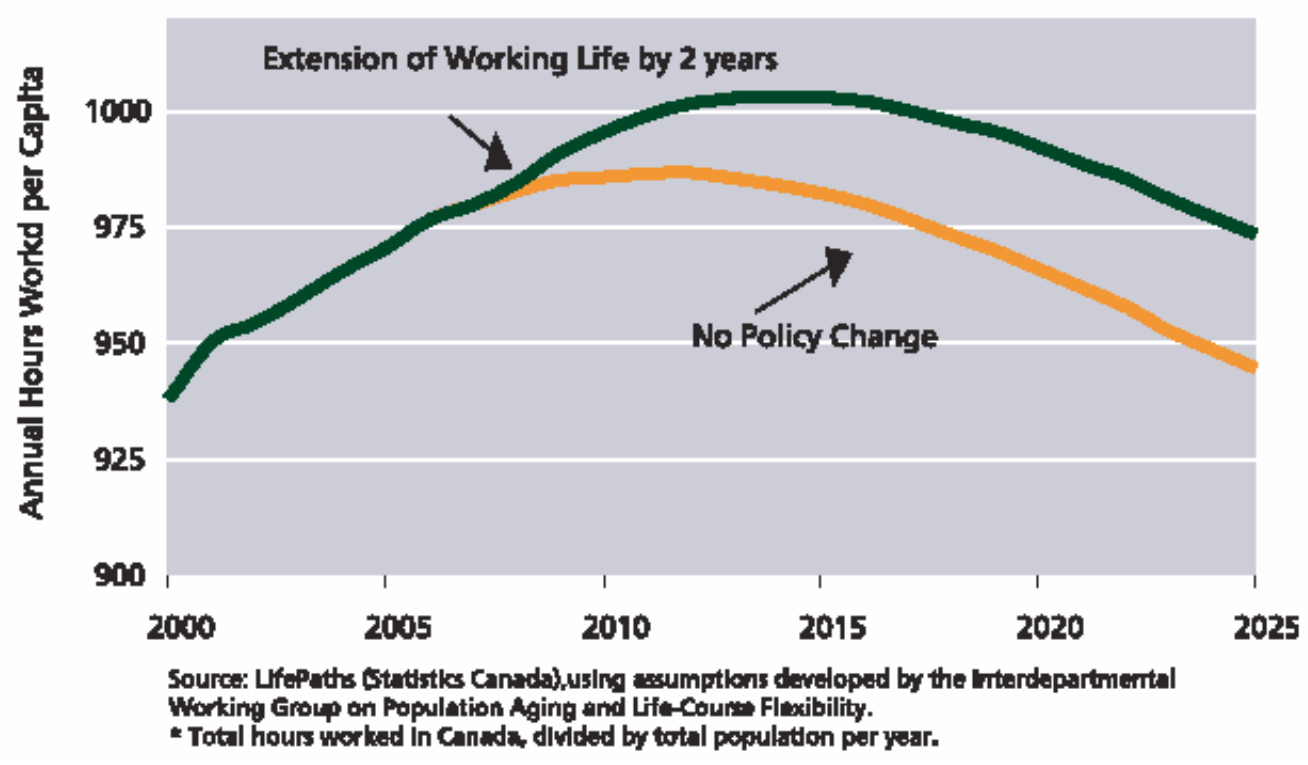

As the PRI study also notes, some of the more apocalyptic discussions of population aging in Canada ignore important bits of good news. In looking at the future impact on health care costs of population aging, in particular, a crucial distinction should be made between age-specific costs and costs incurred in the last year of life, since there is a huge difference between health care costs in the last year of people's lives and in earlier years ${ }^{3}$. From this perspective, increased life expectancy means delaying the health care costs that eventually come with the final year of life - not a fundamental increase in age specific costs. The increase in health care costs as a percentage of GDP due to population aging varies, in different estimates, between $2.6 \%$ and $4.2 \%$ of GDP ${ }^{4}$. These are significant numbers but none of these estimates imply a rate of health care spending, as a percentage of GDP, that is anything greater than current US levels.

As well, Canadian pension plans are in considerably better financial health than the pension systems of many other OECD nations and, since birth rates in Canada fell later, and less, than in other OECD nations (except the US), the Canadian experience

\footnotetext{
${ }^{3}$ For example, males over the age of 65 cost the health care system in Canada an average of $\$ 666$ per year if they are not in their last year of life, but $\$ 29,181$ if they are in their last year. The difference for females over 65 is even greater - $\$ 545$ if not in their last year, but $\$ 50,956$ in the last year. (PRI, 2005:15)

${ }^{4}$ PRI (2005:16)
} 
with population aging will not be as sudden or severe as in many European countries. An increasing fraction of Canada's senior citizens have also been able, in recent years, to rely on CPP benefits instead of having to draw on income tested transfers from the Guaranteed Income Supplement. And the flip side of our past tax exemption of contributions to registered pension plans and RRSPs is that this retirement income is taxable when it is withdrawn - so the gap between seniors' percentage of the population and their percentage of income taxes paid is steadily narrowing.

These factors are worth reviewing because they tend to offset somewhat the sense of apocalyptic crisis that sometimes suffuses the debate on population aging - but even if it is agreed that "things could be worse", some policy changes are still called for. In particular, in applied policy discussions one often sees the position expressed (e.g. by Matte, 2005) that because population aging means a slowing of GDP growth, the retirement age should be raised to forestall this.

If GDP growth were all that mattered, it would be trivially easy to engineer a delay in retirement to offset the labour force impacts of population aging. One only has to recreate the incentive structure of the 1921, when $58.4 \%$ of males 65 and over were in the labour force, or the incentives of 1931, when 55.7\% were ${ }^{5}$. By all the evidence, the 65 and over population of the 1930s was in poorer health than today's senior citizens, and had to work in jobs that tended to be more physically demanding. Yet they worked all their lives, because if people need the money badly enough, they have little option. And when people reach their sixties without significant savings (either in home equity or in financial assets) and without pension rights, they need to keep earning income.

In 2004 , only $11.8 \%$ of males aged 65 and over (and $4.5 \%$ of females) were in the labour force - so if GDP growth were all that mattered, there is substantial room for increase in labour supply, which could be engineered simply by setting up a system in which somewhat more of the retirement age cohort arrives each year at age 65 with little financial option but to keep working. There has been a significant decline in registered pension plan coverage in Canada in recent years - from $44.6 \%$ of paid workers in 1993 to $39.6 \%$ in $2002^{6}$. If fewer future retirees can look forward to private pensions, their need for income to supplement public pensions will therefore depend heavily on trends in asset ownership (i.e. the percentage of each birth cohort who arrive at retirement age without significant private wealth).

The stock of wealth that an individual has at age 65 depends on their entire prior life sequence of earnings, savings and life events - and there are many possible shocks to lifetime savings profiles. Periods of illness or unemployment or withdrawal from the labour force interrupt earnings, market swings affect asset values and events like divorce divide household possessions. Although other events may partially offset negative shocks (e.g. remarriage will pool household assets ${ }^{7}$ anew) and although individuals can vary their savings rates somewhat in response to past shocks, the time and means available to

\footnotetext{
${ }^{5}$ Woods and Ostry (1962:309)

${ }^{6}$ Source: ESTAT, Statistics Canada, Catalogue no. 74-507-XCB and 13F0026MIE-2004001. Last modified: 2004-09-15.

${ }^{7}$ To be more precise, it is household assets net of legal expenses that will be recombined in merged, previously divorced households - as a depressingly large fraction of Canada's population can attest, divorce has a significant impact on asset acquisition.
} 
recover from financial shocks does eventually run out. In the end, those who have had a series of relatively bad draws end up without much by way of assets.

Moreover, each cohort of Canadians also draws from a different distribution of life experiences. Those Canadians who turned 60 in 2005 are the birth cohort of 1945, who just preceded the "baby boom". They entered the labour market in the 1960s when unemployment averaged 5.0 percent and spent their early years in 1970s labour markets when unemployment averaged 6.7 per cent and real wages were growing strongly. New graduates of that era faced the problem of which job to choose, but it was largely taken for granted that a "job" was a full-time, full-year, continuing employment relationship, often protected by a collective agreement or some contractual guarantee of "permanent" status. The welfare state was expanding, and the introduction of medicare, public pension plans and a more generous unemployment insurance system progressively removed much of the economic risk associated with illness, old age and unemployment.

Since the young workers of the 1960s were the senior employees of the 1990s, this cohort initially enjoyed the implicit security offered by the ready availability of alternative employment in a strong labour market, and most had the explicit security of seniority protections against layoffs in the slack labour markets of the 1980s and 1990s. For this fortunate cohort, an expectation of a secure old age, following a working life of secure employment, was not unreasonable. Nevertheless, a significant fraction have still ended their working life without significant assets. Paying off the mortgage on an owneroccupied home and acquiring RRSP savings are the primary savings strategies available to working Canadians. However, the 1999 Survey of Financial Security found that among those people then aged 55 to 64 years old (i.e. the cohort borne between 1935 and 1944), only $75 \%$ owned homes (median value $\$ 130,000$ ) - i.e. $25 \%$ were renting - and only $67 \%$ owned RRSPs (median value \$50,000) - which implies that a third had no RRSPs and another third had less than $\$ 50,000$ in RRSP savings ${ }^{8}$. In total, Shillington (2003:3) calculated that $21 \%$ of the households near retirement (i.e. 55-64) in 1999 had no retirement savings at all, and the savings of the next richest $32 \%$ of households averaged only $\$ 40,000$ - an amount which he terms "futile".

The environment for savings faced by this pre baby boomer cohort was relatively benign compared to that facing later cohorts, who have encountered more severe earnings shocks for many years, due to the combination of higher unemployment rates in the 1980s and 1990s and steadily lower protection from unemployment insurance, plus a structural shift to self-employment and "non-standard" employment forms. For present purposes, the important issue is not trends in the average savings of older cohorts - rising income inequality means that it is quite possible (indeed likely) to observe both an increase in the average savings rate (reflecting the increased savings of richer upper income groups) and an increase in the percentage of each cohort with nil savings. Rather, the important issue for the labour force participation of older Canadians in future years is whether an increasing fraction of the population will arrive at age 65 finding that their savings plans have been derailed by events, and their choices now are whether to depend entirely on CPP, OAS and GIS payments or to continue working.

Much of the discussion of the continued labour force participation of older Canadians has revolved around the facilitation of further employment by those older Canadians who want to keep working. There are important issues of mandatory

\footnotetext{
${ }^{8}$ - see Tables 3.10b and 3.10c (Statistics Canada :2001).
} 
retirement, pension plan administration and entitlement, employer discrimination and workplace design to be addressed. Gunderson (1998) has, for example, discussed the financial incentives now implicit in private pension plans, CPP/QPP and RRSP administration which tilt the balance towards complete labour force withdrawalafter 65 , rather than continued employment. Within the current CPP/QPP design, these supply-side incentives ${ }^{9}$, likely would have a fairly modest impact - but one could also imagine improving incentives by sweetening CPP pensions with "bonus benefits" calculated on earnings after age $65^{10}$. As well, as the PRI (2005:31) emphasizes, one must recognize the importance of the structure of labour demand. Because a phased, gradual withdrawal from their current employment seems to be what many older workers want, employers need to redesign jobs, re-evaluate attitudes towards older workers and renegotiate existing provisions for mandatory retirement in collective agreements.

However, although these initiatives are all worthwhile, the debate on longer labour force participation should not be framed just in terms of incentives and continued job satisfaction - e.g. of upper middle class professionals with heavy psychological investments in their occupational identity, and healthy pensions. A trend to longer (voluntary) working lives can correspond to greater well-being, but later retirement can also be a consequence of the experience of greater economic insecurity during the working years and an indicator of declining individual welfare.

As Jones (2004) notes, the national B/U ratio (the number of EI regular benefit recipients as a fraction of the number of unemployed) now lies around $45 \%$, having remained relatively stable at this level for the past few years. Historically, the ratio varied in the $65-85 \%$ range in the 1970 s and 1980 s and, after reaching a local maximum at $83 \%$ in 1989 , it declined dramatically in the subsequent decade ${ }^{11}$. The Benefit/Wage replacement ratio has similarly been cut drastically over the years. Together with the long term trend to declining generosity of Social Assistance ${ }^{12}$, these trends imply that future cohorts of retirees will have been much more exposed to adverse shocks to their lifetime savings plans than was typical during the working lives of the retirees of recent years (e.g. the 1995 to 2005 retiree cohort). And although early RRSP withdrawals may often now be the financial mechanism which enables households to manage through periods of low income, this clearly comes at the cost of its intended function of retirement savings. Hence, the likelihood is that in coming decades Canada will see rising labour force

\footnotetext{
${ }^{9}$ For example, both Gundersen and the PRI argue for adjustments to the actuarial adjustment for early and late retirement, work cessation test and continued accrual of benefits for CPP benefits - but the relatively small size of maximum CPP benefits, and the marginal nature of each reform, together imply that one cannot expect large impacts.

${ }^{10}$ The incentive value of such "bonus benefits" would depend on perceptions (or perhaps distaste for reliance on means tested transfers) since additional pension entitlements under CPP imply, for many seniors, substantial tax back of GIS payments, plus higher income tax payments - see Shillington (2003:2) for calculations of the marginal tax rates facing seniors, which can easily be 0.75 , or even more. These high implicit tax rates imply a relatively low fiscal cost to government of a CPP bonus on earnings $65+$. Nevertheless, for the same reason that paying overtime rates induces more labour supply than flat rate wage increases, introducing a CPP bonus to continued employment after 65 would increase incentives at the margin.

${ }^{11}$ The Canada Employment Insurance Commission prefers to stress the percentage of potentially eligible claimants who receive benefits - thereby removing the unemployed who are considered ineligible from consideration of the adequacy of UI/EI coverage (see Jones, 2004 for a full discussion).

${ }^{12}$ See NATIONAL COUNCIL OF WELFARE (2005)
} 
participation among seniors partly because greater risk exposure over the life cycle will have the consequence that more people, over time, will have runs of bad luck that leave them still needing a job at age 65 .

The issue, of course, for social policy is that we would like to improve economic well-being, not reduce it. If improving well-being is the objective, then a major purpose in encouraging rising labour force participation among senior citizens is as a way to enable individuals to improve their allocation of time over the life cycle - i.e. to improve their options for choices to continue in paid employment. [And we should also encourage more family-friendly policies to enable middle aged Canadians to reduce labour supply.] If improving well-being is the objective, policy design should not set things up so that more Canadians have little choice but to work as long as they can-which implies that it is time to revisit the issue of income security for working Canadians. The EI reforms of 1996 were heavily influenced by the perceived budget crisis of the federal government at that time (and a surplus on the EI account has since been a significant contributor to the federal budget balance) - now that federal finances are in surplus, it is time to think again about unemployment insurance.

There is an enormous international literature on the incentive effects of unemployment insurance for workers and for firms and on the optimal allocation of employment income risk. Greater economic security for the current work force has direct benefits for risk averse workers ${ }^{13}$, but the details of design are crucially important to both equity and efficiency impacts. As well, in the Canadian context, there is the added complication that the UI/EI system has been so often used as a basis for negative regional stereotyping that it has become, in itself, a magnet for inter-regional bickering and alienation. One can, however, increase the insurance value of EI by marginal changes to some of its current eligibility provisions (e.g. to deal with the difficulties faced by reentrants or the long term unemployed) and by increasing maximum insurable earnings. As well, it may also be time to think of new initiatives, such as a supplemental system of earmarked tax exempt accounts (which might be called an "Earnings Interruption Savings Plan") to help reduce consumption risk volatility, while avoiding the opprobrium that is attached to the current EI system.

A detailed examination of options for EI reform lies beyond the scope of this paper. Nevertheless, it is clear that the situation individuals face as they enter their sixties reflects the accumulated implications of the options, choices and hazards that they encountered over their prior working lives. The past decade has seen a substantial increase in the lifetime risk exposure of Canadian workers and one must expect that this will affect the fraction of future cohorts who arrive at 65 still needing employment income. There is a substantial role for public policy to play in evening out labour supply over the life cycle and encouraging the continued voluntary participation in the labour force of the baby boom cohort. But if an increased employment rate for senior citizens is to correspond with an increase in economic well-being, rather than a decrease, it should be a choice, not a necessity - and greater income security for Canada's current workers is a necessary precondition.

\section{References}

${ }^{13}$ For an empirical calculation, see Osberg, Erksoy and Phipps (1998) 
Jones, Stephen R.G. (2004) Review of the Employment Insurance Coverage Measures Final Report for HRSDC Contract 9431-04-0004 / 00, October 21, 2004

Gunderson, Morley (1998) Flexible Retirement as an Alternative to 65 and Out The Pension Papers C.D. Howe Institute Toronto

Matte, Bernard (2005) "Labour Market Information and Analysis: Their Contribution to Economic Prosperity - Recent Examples and Future Paths for Quebec" EmploiQuébec presentation to National Labour Market Information Forum - Forum of Labour Market Ministers - Labour Market Information Working Group -Halifax November 8-9, 2005 see http://www.flmmlmi.org/LMIForum2005/english/presentation/pre bernard matte 2005 en.pdf

NATIONAL COUNCIL OF WELFARE (2005) WELFARE INCOMES 2004 Ottawa, SPRING 2005 REVISED AUGUST 2005

OECD (2005) Aging and Employment Policies - Canada Paris, 2005

Osberg, Lars, Sadettin Erksoy and Shelley Phipps (1998) "How to Value the Poorer Prospects of Youth in the early 1990s?" Review of Income and Wealth.

Series 44, No.1, March 1998, pp. 43-62

Osberg, Lars and Andrew Sharpe(2005) 'How should we measure the 'Economic' Aspects of Well-Being?" Review of Income and Wealth Series 51, Number 2, June 2005 Pp. 311-336

Paquet, Marie-France Timothy C. Sargent and Steven James (2000) Forecasting Employment Rates: A Cohort Approach Department of Finance Working Paper 2000-06

Policy Research Initiative (2005) Encouraging Choice in Work and Retirement Project Report October 2005

Shillington, Richard (2003) New Poverty Traps: Means-Testing and Modest-Income Seniors C.D. Howe Institute Backgrounder No. 65, April 2003

Statistics Canada (2001) The Assets and Debts of Canadians: An overview of the results of the Survey of Financial Security Catalogue no. 13-595-XIE

Woods, H.D. and S. Ostry (1962) Labour Policy and Labour Economics in Canada MacMillan of Canada, Toronto 1962 